Brit. Heart F., 1967, 29, 778.

\title{
. Q-1 or C-1 Interval in the Diagnosis of Mitral Stenosis
}

\author{
VESSELIN I. ORESHKOV \\ From the Department of Medicine, Higher Medical Institute, Sofia, Bulgaria
}

The delay of the first heart sound is a well-known characteristic sign of mitral stenosis. This phenomenon is due to increased left atrial pressure, delayed rise in left ventricular pressure (especially after a short diastole), and rigid mitral cusps (Wells, 1957). The delay in the first mitral sound is usually assessed by the transformation time (or Q-1 interval). But this interval has often been found to be of little diagnostic value. The Q-1 interval is not always prolonged in mitral stenosis (Chavez, Vaquero, and Mendoza, 1955; Rich, 1959; Maslyuk, 1959). No definite correlation has been established between the Q-1 interval and the mitral valve size (Donnelly, Maha, and Orgain, 1959; Hager et al., 1965), the pulmonary capillary pressure (Warembourg et al., 1964), the pulmonary artery pressure (Lukomsky, 1965), and the right ventricular pressure (Lee, Scherlis, and Singleton, 1965). There has been only a slight correlation between the Q-1 interval and both the left atrial pressure and the mitral atrio-ventricular gradient (Proctor et al., 1958). The Q-1 interval may be prolonged even in patients with pure mitral regurgitation (Sokolova, 1964).

To study the actual delay of the first mitral sound, the apex cardiogram was used, as a simple and correct method for recording the onset of the movements of the heart in systole. There is a very close correlation between the initial abrupt rise on the apex cardiogram and the initial rise of the left ventricular pressure curve (Tavel et al., 1965a). In this respect, the apex cardiogram is a direct method of recording, while the rise in ventricular pressure appears as a result of the muscular contraction and may show some lag in comparison with the apex cardiogram. On the average, the curve on the apex cardiogram starts to rise slightly before the pressure curve (Tafur, Cohen, and Levine, 1964), with an average difference of $7 \pm 3 \mathrm{msec}$. (Tavel et al., 1965a).

Received October 26, 1966.
This subject was discussed in detail in a previous work (Oreshkov, 1965). The use of the apex cardiogram makes it possible to exclude the socalled electromechanical delay, i.e. the time interval between the onset of the QRS and the onset of the ventricular contraction ( $Q-C$ interval; $C$ from contraction-Tavel et al., 1965a) (Fig. 1). The interval between the onset of the systolic wave of the apex cardiogram and the first mitral sound represents the initial phase of ventricular contraction, before the atrio-ventricular valves close, which the author designated C-1 interval.

\section{SUBJECTS AND METHODS}

Studies were made on 57 women and 20 men with mitral valve disease; their ages ranged from 15 to 56 years. Of these 77 patients, 45 had mitral stenosis (Group I), 21 had predominant mitral stenosis (Group II), 4 had mitral stenosis and regurgitation, approximately of an equal degree (Group III), and 7 had pure or predominant mitral regurgitation (Group IV). In all patients the diagnosis was confirmed by cardiac operation (63 patients), by cardiac catheterization (13 patients), or by angiocardiography (1 patient). There were 2 control groups: 40 normal subjects, and 27 hypertensive patients.

Lead II of the electrocardiogram, a left ventricular apex cardiogram from the apex beat, and a medium frequency phonocardiogram (140 and 250 cycles per second) at the mitral area were recorded simultaneously. The tracings were made in left lateral decubitus position of the patient at the end of expiration or at the beginning of inspiration. For identification of the origin of the apex cardiogram (right or left apex beat) the configuration of the QRS complex from the point of maximal cardiac impulse was used. A pulse wave (linear) condenser microphone (Boucke-Brecht) for recording the apex cardiogram, and a piezo-electric microphone for recording the phonocardiogram were used, connected with a direct-writing multichannel recorder (Hellige, Model 9400/6). The records were taken at a paper speed of $50 \mathrm{~mm}$. $/ \mathrm{sec}$. with $20 \mathrm{msec}$. time lines. For 78 each measurement a minimum of three consecutive 
TABLE I

Q-C, C-1, Q-1, AND Q-1 1 INTERVALS IN NORMAL SUBJECTS, HYPERTENSIVE PATIENTS, AND PATIENTS WITH MITRAL VALVE DISEASE

\begin{tabular}{|c|c|c|c|c|c|c|c|c|c|c|c|c|c|}
\hline \multirow{2}{*}{ Groups * } & \multirow{2}{*}{$\begin{array}{c}\text { No. of } \\
\text { cases }\end{array}$} & \multicolumn{3}{|c|}{ Q-C (msec.) } & \multicolumn{3}{|c|}{ C-1 (msec.) } & \multicolumn{3}{|c|}{ Q-1 (msec.) } & \multicolumn{3}{|c|}{ Q-1 } \\
\hline & & Range & Mean & S.D. & Range & Mean & S.D. & Range & Mean & S.D. & Range & Mean & S.D. \\
\hline \multirow{2}{*}{$\begin{array}{c}\text { A } \\
\text { B } \begin{array}{c}\text { Normal subjects } \\
\text { Hypertensive } \\
\text { patients }\end{array}\end{array}$} & 40 & $20-50$ & $28 \cdot 5$ & $\pm 8 \cdot 0$ & $20-50$ & $30 \cdot 5$ & $\pm 7 \cdot 1$ & $50-90$ & $59 \cdot 0$ & $\pm 8 \cdot 3$ & - & - & - \\
\hline & 27 & $20-60$ & $34 \cdot 5$ & \pm 9.9 & $10-60$ & $32 \cdot 8$ & $\pm 10 \cdot 2$ & $50-100$ & $67 \cdot 3$ & $\pm 12 \cdot 7$ & - & 一 & - \\
\hline Group I (total) & 45 & $10-50$ & $27 \cdot 6$ & \pm 6.9 & $30-65$ & $47 \cdot 4$ & $\pm 8 \cdot 1$ & $55-100$ & $75 \cdot 0$ & $\begin{array}{r} \pm 9 \cdot 4 \\
-\end{array}$ & $56 \cdot 0-101 \cdot 6$ & $74 \cdot 1$ & $\pm 10 \cdot 7$ \\
\hline $\begin{array}{l}\text { Group Ia } \\
\text { Group Ib } \\
\text { Group Ic } \\
\text { Group Id }\end{array}$ & $\begin{array}{r}16 \\
20 \\
7 \\
2\end{array}$ & $\begin{array}{l}10-50 \\
10-40 \\
20-40 \\
30-35 \\
\cdots\end{array}$ & $\begin{array}{l}28 \cdot 1 \\
26 \cdot 25 \\
28 \cdot 6 \\
32 \cdot 5\end{array}$ & $\begin{array}{r} \pm 8.9 \\
\pm 5.4 \\
\pm 6.3 \\
\pm 3.7\end{array}$ & $\begin{array}{l}35-65 \\
40-60 \\
30-60 \\
35-40\end{array}$ & $\begin{array}{r}50 \cdot 9 \\
47 \cdot 7 \\
41 \cdot 4 \\
37 \cdot 5 \\
-\end{array}$ & $\begin{array}{r} \pm 7.4 \\
\pm 6.8 \\
\pm 9.3 \\
\pm 3.6 \\
--.-\end{array}$ & $\begin{array}{l}70-100 \\
60-90 \\
55-90 \\
65-75 \\
\ldots\end{array}$ & $\begin{array}{l}79 \cdot 1 \\
74 \cdot 0 \\
70 \cdot 0 \\
70 \cdot 0 \\
-\cdots-.\end{array}$ & $\begin{array}{r} \pm 8 \cdot 0 \\
\pm 9 \cdot 4 \\
\pm 11 \cdot 2 \\
\pm 7 \cdot 1 \\
----\end{array}$ & $\begin{array}{r}63 \cdot 0-101 \cdot 6 \\
56 \cdot 0-92 \cdot 0 \\
57 \cdot 0-86.0 \\
65.0-71.0 \\
\end{array}$ & $\begin{array}{l}78 \cdot 5 \\
72 \cdot 3 \\
70 \cdot 8 \\
68 \cdot 0\end{array}$ & $\begin{array}{r} \pm 10.6 \\
\pm 10.8 \\
\pm 10.5 \\
\pm 4.2 \\
\end{array}$ \\
\hline $\begin{array}{l}\text { Group II } \\
\text { Group III } \\
\text { Group IV }\end{array}$ & $\begin{array}{r}21 \\
4 \\
7\end{array}$ & $\begin{array}{l}10-40 \\
25-40 \\
20-70\end{array}$ & $\begin{array}{l}27 \cdot 9 \\
32 \cdot 5 \\
40 \cdot 0\end{array}$ & $\begin{array}{r} \pm 7 \cdot 0 \\
\pm 6.5 \\
\pm 16.6\end{array}$ & $\begin{array}{l}30-60 \\
30-50 \\
25-40\end{array}$ & $\begin{array}{l}45 \cdot 2 \\
41 \cdot 3 \\
31 \cdot 4\end{array}$ & $\begin{array}{l} \pm 7 \cdot 3 \\
\pm 8 \cdot 5 \\
\pm 4 \cdot 8\end{array}$ & $\begin{array}{l}60-90 \\
70-80 \\
60-100\end{array}$ & $\begin{array}{l}73 \cdot 1 \\
73 \cdot 7 \\
71 \cdot 4\end{array}$ & $\begin{array}{r} \pm 7 \cdot 2 \\
\pm 4 \cdot 8 \\
\pm 14 \cdot 6\end{array}$ & $\begin{array}{l}54 \cdot 4-90 \cdot 0 \\
64 \cdot 8-79 \cdot 8 \\
59 \cdot 2-116 \cdot 0\end{array}$ & $\begin{array}{l}73 \cdot 7 \\
74 \cdot 3 \\
73 \cdot 7\end{array}$ & $\begin{array}{r} \pm 8 \cdot 0 \\
\pm 7 \cdot 2 \\
\pm 19.8\end{array}$ \\
\hline
\end{tabular}

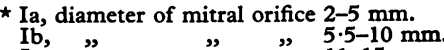

Ic, " $\quad$ " " " $\quad$ " $11-15 \mathrm{~mm}$

$\dagger c=$ corrected values to a standard heart rate of $75 / \mathrm{min}$. ( $R-R=800 \mathrm{msec}$.).

cycles was used. Where there was atrial fibrillation three (rarely less) separate cycles of approximately $800 \mathrm{msec}$. duration were chosen.

\section{RESULTS}

The results are given in Table $\mathrm{I}$.

The electromechanical delay ( $\mathrm{Q}-\mathrm{C}$ interval) in the control groups varied between 20 and $60 \mathrm{msec}$. with an average of $28.5 \mathrm{msec}$. in the normal subjects, and in the patients with mitral valve disease between 10 and 70 msec., with an average of 29.0 msec. In the majority of all the subjects examined, this interval was found to be between 20 and $40 \mathrm{msec}$., which corresponds to the published values: mean $20 \mathrm{msec}$. (Hartman and Snellen, 1960), mean $35 \mathrm{msec}$ (Coghlan, Prieto, and Harrison, 1961), 10-40 msec. (Zuckermann, 1961), mean $23 \mathrm{msec}$. (Warembourg and Ducloux, 1963), 20-30 msec. (Lohr, Vollenhoven, and Rotterdam, 1963), and mean 21 msec. (Tafur et al., 1964). In the patients with pure or predominant mitral regurgitations (Group IV) only, the mean value of the $\mathrm{Q}-\mathrm{C}$ interval was considerably higher than in the other groups, which was mainly due to the unusually long interval (70 msec.) in one of the patients.

The initial phase of ventricular contraction (C-1 interval) normally was $30.5(20-50)$ msec., and in the hypertensive patients-32.8 (10-60) msec. These values are close to those found by other authors: 44 (21-82) msec. (Coulshed and Epstein, 1963); 37 (0-50) msec.-_deformation phase" (Warembourg and Ducloux, 1963); mean $35 \mathrm{msec}$. - "pre-isometric phase" (Tafur et al., 1964). The maximum prolongation of the C-1 interval was found in Group I (mean 47.4 msec.) and Group II (mean 45.2 msec.). There was a good correlation between the duration of the C-1 interval and the long diameter of the mitral orifice (Tables I and II). In the patients with pure or predominant mitral regurgitation (Group IV) this interval was normal. Sixty-two per cent of the individual values of the

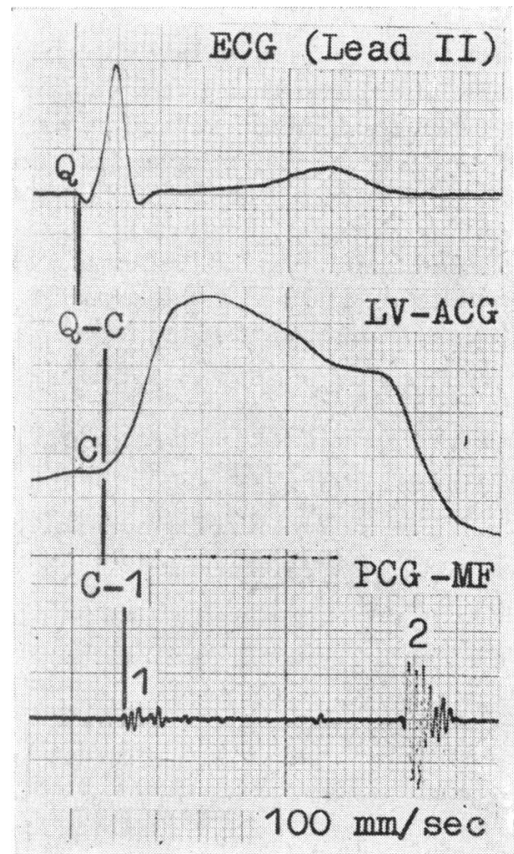

Fig. 1.-Record taken from a normal subject aged 20 . Q-C interval $=30 \mathrm{msec}$; C-1 interval $=25 \mathrm{msec}$. ECG $=$ electrocardiogram, LV-ACG = left ventricular apex cardiogram, $\mathrm{C}=$ contraction (onset of the systolic wave in the ACG), PCG-MF = phonocardiogram-medium frequency, $1=$ first heart sound, 2 = second heart sound. 
TABLE II

C-1, Q-1, AND Q-1 1 INTERVALS: STATISTICAL DATA FOR THE RELIABILITY OF DIFFERENCES BETWEEN THE VARIOUS GROUPS EXAMINED

\begin{tabular}{|c|c|c|c|c|c|c|c|c|}
\hline \multirow{2}{*}{\multicolumn{3}{|c|}{ Groups * }} & \multicolumn{2}{|c|}{ C-1 } & \multicolumn{2}{|c|}{ Q-1 } & \multicolumn{2}{|c|}{ Q-1 $c$} \\
\hline & & & $\mathbf{t}$ & $\mathbf{p}$ & $t$ & $\mathbf{p}$ & $t$ & $\mathbf{p}$ \\
\hline $\begin{array}{l}\text { Group Ia + } \\
\text { Group Ib + } \\
\text { Group Ic + } \\
\text { Group Id + } \\
\text { Group II + } \\
\text { Group III + } \\
\text { Group IV + } \\
\end{array}$ & $\begin{array}{l}\text { rma } \\
\text { " } \\
\text { ", } \\
\text { " } \\
\end{array}$ & $\begin{array}{l}\text { abjects } \\
" \\
" \\
" \\
" \\
"\end{array}$ & $\begin{array}{l}9 \cdot 44 \\
9 \cdot 15 \\
2 \cdot 96 \\
2 \cdot 52 \\
7 \cdot 77 \\
2 \cdot 46 \\
0 \cdot 42 \\
\end{array}$ & $\begin{array}{l}<0.001 \\
<0.001 \\
<0.01 \\
<0.02 \\
<0.001 \\
<0.02 \\
>0.50\end{array}$ & $\begin{array}{l}8 \cdot 41 \\
6 \cdot 05 \\
2 \cdot 48 \\
2 \cdot 11 \\
6 \cdot 84 \\
5 \cdot 38 \\
2 \cdot 19\end{array}$ & $\begin{array}{l}<0.001 \\
<0.001 \\
<0.02 \\
<0.05 \\
<0.001 \\
<0.001 \\
<0.05\end{array}$ & & \\
\hline \multicolumn{3}{|c|}{$\begin{array}{l}\text { Groups Ia and Ib } \\
\text { Groups Ia and Ic } \\
\text { Groups Ia and Id } \\
\text { Groups Ib and Ic } \\
\text { Groups Ib and Id } \\
\text { Groups Ic and Id }\end{array}$} & $\begin{array}{l}1 \cdot 34 \\
2 \cdot 40 \\
4 \cdot 26 \\
1 \cdot 65 \\
3 \cdot 43 \\
1 \cdot 13\end{array}$ & $\begin{array}{l}<0.25 \\
<0.05 \\
<0.001 \\
<0.25 \\
<0.01 \\
<0.50\end{array}$ & $\begin{array}{l}1 \cdot 76 \\
1.94 \\
1.68 \\
0.85 \\
0.73 \\
0\end{array}$ & $\begin{array}{l}<0.10 \\
<0.10 \\
<0.25 \\
<0.50 \\
<0.50 \\
\end{array}$ & $\begin{array}{l}1 \cdot 73 \\
2 \cdot 15 \\
2.63 \\
0.32 \\
1 \cdot 12 \\
0.56\end{array}$ & $\begin{array}{l}<0.10 \\
<0.05 \\
<0.02 \\
>0.50 \\
<0.50 \\
>0.50\end{array}$ \\
\hline \multicolumn{3}{|c|}{$\begin{array}{l}\text { Groups Ia and IV } \\
\text { Groups Ib and IV } \\
\text { Groups Ic and IV } \\
\text { Groups Id and IV } \\
\end{array}$} & $\begin{array}{l}7 \cdot 53 \\
6 \cdot 91 \\
2 \cdot 53 \\
1 \cdot 95\end{array}$ & $\begin{array}{l}<0.001 \\
<0.001 \\
<0.05 \\
<0.10\end{array}$ & $\begin{array}{l}1 \cdot 31 \\
0 \cdot 44 \\
0 \cdot 20 \\
0 \cdot 19\end{array}$ & $\begin{array}{l}<0.25 \\
>0.50 \\
>0.50 \\
>0.50\end{array}$ & $\begin{array}{l}0.61 \\
0.18 \\
0.34 \\
0.71\end{array}$ & $\begin{array}{l}>0.50 \\
>0.50 \\
>0.50 \\
=0.50\end{array}$ \\
\hline \multicolumn{3}{|c|}{$\begin{array}{l}\text { Groups II and III } \\
\text { Groups II and IV } \\
\text { Groups III and IV }\end{array}$} & $\begin{array}{l}0 \cdot 87 \\
5 \cdot 82 \\
2 \cdot 15\end{array}$ & $\begin{array}{l}<0.50 \\
<0.001 \\
<0.10\end{array}$ & $\begin{array}{l}0 \cdot 21 \\
0 \cdot 29 \\
0 \cdot 38\end{array}$ & $\begin{array}{l}>0.50 \\
>0.50 \\
>0.50\end{array}$ & $\begin{array}{l}0 \cdot 15 \\
0 \\
0 \cdot 07\end{array}$ & $\begin{array}{l}>0.50 \\
>\overline{0.50}\end{array}$ \\
\hline
\end{tabular}

* For explanation of Groups see text, and footnote to Table I.

C-1 interval in Groups I and II did not overlap those in Group IV (Fig. 2). The values of the C-1 interval in Group III lay between those of Groups I and IV.

In a series of 15 patients with mitral stenosis (diameter of the mitral orifice from 2 to $13 \mathrm{~mm}$.), who were examined before valvotomy and two to three weeks later, the C-1 interval shortened from mean $51 \cdot 3(40-65)$ msec. to mean $38 \cdot 3(30-60)$ msec.

The transformation time (Q-1 interval) varied less in the separate groups. The values in the patients with mitral valve disease exceeded the normal ones,

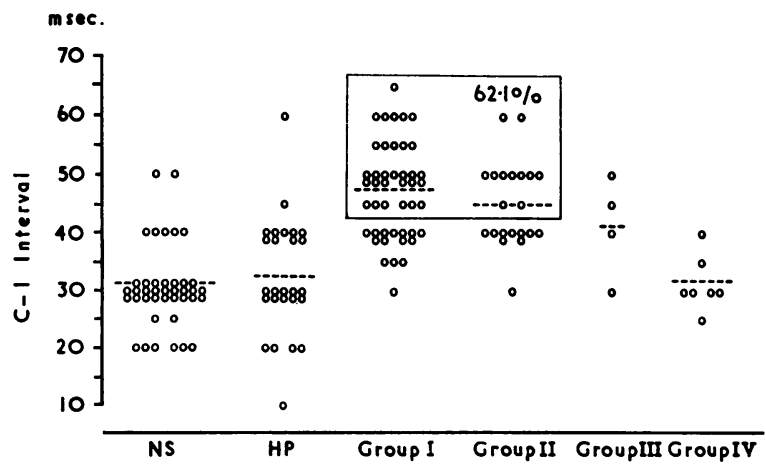

Fig. 2.-Individual values of the $\mathrm{C}-1$ interval in normal subjects (NS), hypertensive patients (HP), and patients with mitral valve disease. The mean values are shown by a dotted line. See text. but they did not differ essentially with respect to the kind of mitral valve disease. Thus, the Q-1 interval averaged $75.0 \mathrm{msec}$. in Group I, $73.1 \mathrm{msec}$. in Group II, $73.7 \mathrm{msec}$. in Group III, and $71.4 \mathrm{msec}$. in Group IV. The correlation between the Q-1 interval and the diameter of the mitral orifice was less conspicuous than that between the C-1 interval and the mitral area (Tables I and II). All the individual values of the Q-1 interval in Groups I and II overlapped those in Group IV. Even when the terminal Q-1 variant of Group IV was excluded, only 10.6 per cent of the individual values in Groups I and II did not overlap those in Group IV (Fig. 3). Similar results were obtained by Proctor et al. (1958).

As is known, the duration of the Q-1 interval in mitral stenosis is inversely proportional to the length of the preceding cardiac cycle (Wells, 1957; Steinzeig et al., 1957; Di Perri and Fabrizi, 1958; Tavel, Feigenbaum, and Campbell, 1965b). Because of this, the Q-1 intervals measured were corrected to a standard heart rate of $75 / \mathrm{min}$. $(\mathrm{R}-\mathrm{R}=800 \mathrm{msec}$.) using the Ježek (1961) formula. The mean corrected values did not differ essentially from those that were not corrected, but the corrected Q-1 intervals in Groups I and II and in Group IV overlapped each other less (Fig. 4) in comparison with those not corrected.

The statistical study also proved that the diagnostic reliability of the C-1 interval was higher in comparison with that of the Q-1 interval (Table II).

It should also be added that the Q-1 interval in the hypertensive patients was considerably longer 


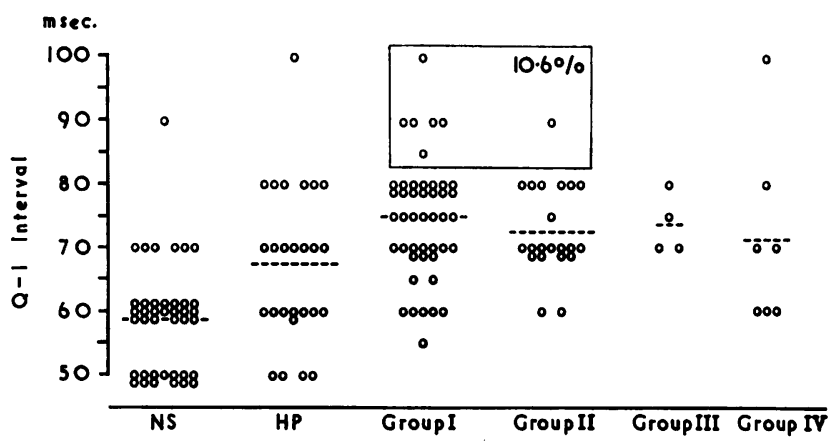

Frg. 3.-Individual values of the $Q-1$ interval in normal subjects (NS), hypertensive patients (HP), and patients with mitral valve disease. The mean values are shown by a dotted line. See text.

than in the normal series, which is well known (Weissler, Leonard, and Warren, 1958; Dack et al., 1960).

\section{Discussion}

Since the prolongation of the transformation time (Q-1 interval) in pure or predominant mitral stenosis is due to a longer initial phase of ventricular contraction (C-1 interval), it is logical that this latter interval should be used in the diagnosis of mitral stenosis. The diagnostic significance of the Q-1 interval diminishes because of the electromechanical delay, which does not vary in relation to the kind of the mitral valve disease. Thus, the electromechanical delay may, to a certain extent,

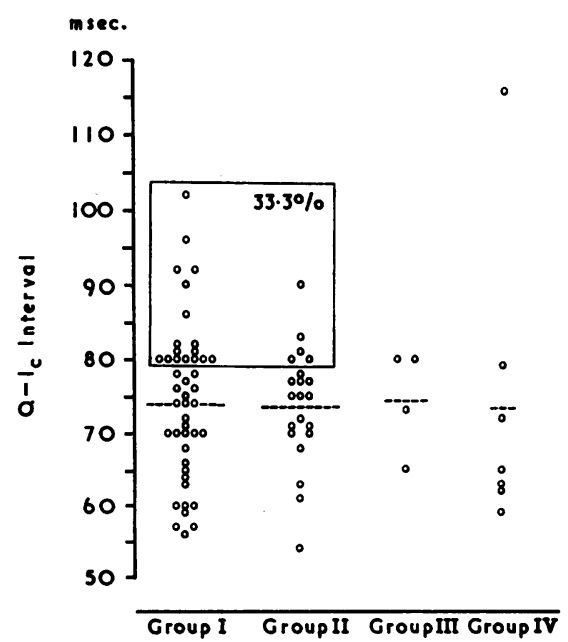

FIG. 4.-Individual values of the Q-1 interval $(=Q-1$ interval corrected to a standard heart rate of $75 / \mathrm{min}$.) in patients with mitral valve disease. See text. straighten out the characteristic differences expected in the duration of transformation time in mitral stenosis and regurgitation. For instance, there are cases of mitral stenosis with very short Q-C interval-10 msec., and very long $\mathrm{C}-1$ interval -60 msec.; the resulting Q-1 interval is at the upper normal limit-70 msec. (Proctor et al., 1958) (Fig. 5A). And, conversely, in some cases of mitral

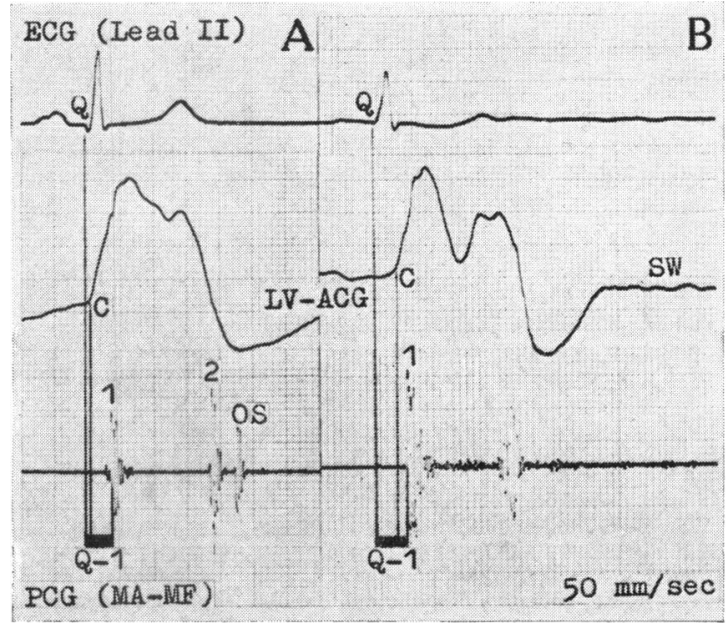

Fig. 5.-A. Record taken from a woman of 25, who had severe mitral stenosis; the valve diameter assessed at operation was $5 \mathrm{~mm}$. Q-1 interval $=70 \mathrm{msec}$. $(\mathrm{Q}-\mathrm{C}=10 \mathrm{msec}$.; $\mathrm{C}-1=$ $60 \mathrm{msec}$.). B. Record taken from a man aged 25, with predominant mitral regurgitation, confirmed by cardiac catheterization. Q-1 interval $=100 \mathrm{msec}$. $(\mathrm{Q}-\mathrm{C}=70 \mathrm{msec}$.; C-1 = 30 msec.). See text. ECG = electrocardiogram, LVACG = left ventricular apex cardiogram, $C=$ contraction (onset of the systolic wave in the ACG), $S W=$ stasis wave, PCG (MA-MF) = phonocardiogram (mitral area-medium frequency), 1 =first heart sound, 2 =second heart sound, OS = opening snap. 
regurgitation there may be an unusually long Q-C interval, for instance $70 \mathrm{msec}$., and a normal C-1 interval-30 msec.; the resulting Q-1 interval is 100 msec., which is characteristic of severe stenosis (Chavez et al., 1955) (Fig. 5B). Warembourg and Ducloux (1963) first reported a longer deformation time of the ventricle (C-1 interval) in cases with mitral stenosis (mean $68.8 \mathrm{msec}$.). But these authors considered both the $\mathrm{C}-1$ and the Q-1 intervals to be of equal diagnostic significance, and they did not find any correlation between the duration of the C-1 interval and the area of the mitral orifice.

Although the Q-1 interval as a whole is dependent on the heart rate, especially in mitral stenosis, the correction of the C-1 interval, because of its shortness, may be avoided without considerably diminishing its diagnostic value. In cases of atrial fibrillation the error would be minimal if cardiac cycles of approximately $800 \mathrm{msec}$. duration were used.

\section{SUMMARY}

The initial phase of the ventricular contraction (C-1 interval), measured from the onset of the systolic wave in the apex cardiogram to the onset of the main vibrations of the first mitral sound in the phonocardiogram, is a more reliable index in the diagnosis of mitral stenosis than the transformation time (Q-1 interval). The C-1 interval shows the actual delay of the first mitral sound. The diagnostic value of the Q-1 interval is diminished by the electromechanical delay, which may change the results.

\section{REFERENCES}

Chavez, I., Vaquero, M., and Mendoza, F. (1955). Etude de 100 malades souffrant de sténose mitrale soumis à la commissurotomie et préalablement cathétérisés. Acta cardiol. (Brux.), 10, 209.

Coghlan, C., Prieto, G., and Harrison, T. R. (1961). Movement of the heart during the period between the onset of ventricular excitation and the start of left ventricular ejection. Amer. Heart f., 62, 65.

Coulshed, N., and Epstein, E. J. (1963). The apex cardiogram: its normal features explained by those found in heart disease. Brit. Heart f., 25, 697.

Dack, S., Bleifer, S., Grishman, A., and Donoso, E. (1960). Mitral stenosis. Auscultatory and phonocardiographic findings. Amer. F. Cardiol., 5, 815.

Di Perri, T., and Fabrizi, G. (1958). The Q-I sound and the II sound-opening snap of mitral valve intervals in mitral stenosis before and after commissurotomy. Cardiologia (Basel), 33, 97.

Donnelly, G. L., Maha, G. E., and Orgain, E. S. (1959). The phonocardiogram as a method for evaluating mitral stenosis. F. thorac. Surg., 37, 200.
Hager, W., Wegehaupt, R., Orth, H. F., and Schley, G. (1965). Die diagnostische Bedeutung des Intervalles Q-I. Herzton im Phonokardiogramm. I. Das Q-I-Intervall bei Normalpersonen, bei arterieller Hypertonie, bei Aortenklappenstenosen und bei Mitralstenosen vor und nach der Operation. Z. Kreisl.-Forsch., 54, 1068.

Hartman, H., and Snellen, H. A. (1960). Proceedings of the Third European Congress of Cardiology, Rome, 1960, Vol. 2, Part B, pp. 711-713.

Ježek, V. (1961). On the so-called Wells' test in mitral stenosis. (In Czech.) Sborn. lék., 63, 313.

Lee, Y.-C., Scherlis, L., and Singleton, R. T. (1965). Mitral stenosis. Hemodynamic, electrocardiographic, and vectorcardiographic studies. Amer. Heart f., 69, 559.

Lohr, H. A., Vollenhoven, E. van, and Rotterdam, A. van (1963). Fundamentals in vibrocardiography. Amer. Heart f., 66, 108.

Lukomsky, P. E. (1965). Recognition of pulmonary hypertension in patients with mitral stenosis without cardiac catheterization. Cor et vasa (Praha), 7, 8.

Maslyuk, V. I. (1959). Phonocardiography in mitral valve disease. (In Russian.) Ter. Arkh., 31 (11), 23.

Oreshkov, V. (1965). Indirect measurement of isovolumetric contraction time on the basis of polygraphic tracing (apex-cardiogram, carotid tracing, and phonocardiogram). Cardiologia (Basel), 47, 315.

Proctor, M. H., Walker, R. P., Hancock, E. W., and Abelmann, W. H. (1958). The phonocardiogram in mitral valvular disease. A correlation of Q-1 and 2-OS intervals with findings at catheterization of the left side of the heart and at mitral valvuloplasty. Amer. F. Med., 24, 861 .

Rich, C. B. (1959). The relation of heart sounds to left atrial pressure. Canad. med. Ass. F., 81, 800.

Sokolova, D. A. (1964). Phasic analysis of cardiac contractility in heart defects. (In Russian.) Kardiologiia, 4, (2), 49.

Steinzeig, S. M., Pinsky, S. T., Alimurung, M. M., and Dimond, E. G. (1957). Phonocardiographic changes in mitral stenosis before and after valvulotomy: a correlation with mitral valve size. Amer. Heart $\mathcal{F}$,, 53, 735.

Tafur, E., Cohen, L. S., and Levine, H. D. (1964). The normal apex cardiogram. Its temporal relationship to electrical, acoustic, and mechanical cardiac events. Circulation, 30, 381.

Tavel, M. E., Campbell, R. W., Feigenbaum, H., and Steinmetz, E. F. (1965a). The apex cardiogram and its relationship to hæmodynamic events within the left heart. Brit. Heart f., 27, 829.

-, Feigenbaum, H., and Campbell, R. W. (1965b). A study of the Q-1 interval in atrial fibrillation with and without mitral stenosis. Circulation, 31, 429.

Warembourg, H., Desruelles, J., Merlen, J. F., Wache, F., Perrard, C., Dubar, P., and Fossati, G. (1964). Rôle du phonocardiogramme dans l'établissement des tracés synchrones. Applications à l'hémodynamique cardiaque. Le chrono-cardiogramme. Acta cardiol. (Brux.), 19, 357.

, and Ducloux, G. (1963). L'apexogramme: application à l'étude des cardiopathies mitrales. Arch. Mal. Cour, 56, 1359.

Weissler, A. M., Leonard, J. J., and Warren, J. V. (1958). Observations on the delayed first heart sound in mitral stenosis and hypertension. Circulation, 18, 165.

Wells, B. G. (1957). Prediction of mitral pressure gradient from heart sounds. Brit. med. F., 1, 551.

Zuckermann, R. (1961). Normale und veränderte Herztöne. Z. Kreisl.-Forsch., 50, 74. 